\title{
Interpreting Intuitions
}

[forthcoming in Third-Person Self-Knowledge, Self-Interpretation, and Narrative eds. Julie Kirsch and Patrizia Pedrini, Springer]

\author{
Marcus McGahhey \\ Georgia State University \\ University of California, San Diego \\ Neil Van Leeuwen ${ }^{1}$ \\ Georgia State University \\ University of Antwerp \\ University of Johannesburg
}

\begin{abstract}
We argue that many intuitions do not have conscious propositional contents. In particular, many of the intuitions had in response to philosophical thought experiments, like Gettier cases, do not have such contents. They are more like hunches, urgings, murky feelings, and twinges. Our view thus goes against the received view of intuitions in philosophy, which we call Mainstream Propositionalism. Our positive view is that many thought-experimental intuitions are conscious, spontaneous, non-theoretical, non-propositional psychological states that often motivate belief revision, but they require interpretation, in light of background beliefs, before a subject can form a propositional judgment as a consequence of them. We call our view Interpretationalism. We argue (i) that Interpretationalism avoids the problems that beset Mainstream Propositionalism and (ii) that our view meshes well with empirical results in contemporary cognitive science.
\end{abstract}

\section{Introduction: Interpretationalism versus Mainstream Propositionalism}

Philosophers tend to talk about intuitions as though they have propositional contents, as in, "I have an intuition that $p$ !" But we should be wary of such talk. Sentences used to describe mental states often mislead in one way or another. One tells a waiter, "I want the roasted Brussels sprouts," when one's desire is really just for hot vegetables. Or one says, "I knew that she would go back on her promise!" when one only really had a murky suspicion. It's a mistake to confuse the nature of a psychological state with the content of a sentence we happen to use in attempting to describe it. This is a familiar point in philosophy of mind. ${ }^{2}$

${ }^{1}$ Authorship is divided equally.

${ }^{2}$ Lewis (1983) and Dennett (1987) both make this point. 
We think talking about intuitions as though they have propositional contents is also misleading. When reporting intuitions in response to thought experiments, philosophers often use that clauses. "My intuition is that Smith's belief is justified and true but not knowledge." "My intuition is that it is wrong to push the man off the bridge." Or, "My intuition is that there is no understanding of Chinese in the room." But such talk creates a misleading impression. The misleading impression is that intuitions always have determinate, consciously-accessible propositional contents.

We call this standard, widely-shared view about intuitions Mainstream Propositionalism and summarize it as follows.

Mainstream Propositionalism: the view that intuitions had spontaneously in response to philosophical thought experiments always have determinate, consciously-accessible propositional contents.

Much of this paper (our negative project) argues that Mainstream Propositionalism is false. Many intuitions prompted by thought experiments (henceforth, thought-experimental intuitions) are not propositional. But if those intuitions are not propositional, what are they like? And how are they incorporated into philosophical theory construction? We argue (our positive project) they are more like hunches, twinges, internal promptings, urgings, or vague suspicions that need to be interpreted before their significance for thought experiments and related philosophical theses is apparent. Our view is Interpretationalism.

Interpretationalism: the view that many intuitions had in response to philosophical thought experiments must be interpreted in light of background beliefs before the intuiter can judge what proposition they support.

We thus hold there are two stages on the route from intuition to propositional judgment. First, the person reading or hearing a thought experiment has an unarticulated, conscious prompting that suggests something is or is not quite right about a philosophical position in relation to a thought-experimental case; this prompting is an intuition. Second, the person having that intuition, by thinking in light of background beliefs, comes to a propositionally articulated judgment ${ }^{3}$ about what exactly is right or wrong about the philosophical position or vignette under consideration. Mainstream Propositionalism-this is its great demerit-conflates the intuition of the first stage with the judgment of the second.

Here's a preview of the paper. Section 2 shows how Mainstream Propositionalism breaks down into four distinct, widely-endorsed claims, where three of them (with some modification) turn out to be still correct on our theory.

\footnotetext{
3 We're using "judgment" here as a catchall term for what could really be a variety of conscious cognitive attitudes, not just conscious beliefs. For example, the output of the interpretive process might be a conscious hypothesis or working assumption. Those differences won't make a difference, however, to the main arguments of this paper.
} 
This overlap gives us confidence that we have many of the same mental states in mind under the term "intuition" as people who hold Mainstream Propositionalism; so our dispute is not merely terminological. Section 3 executes our negative project, giving three arguments against Mainstream Propositionalism: one phenomenological; a second from divergences over how intuitions are reported and described; and a third from unification with the psychology of linguistic intuitions about fictional sentences. Section 4 presents Interpretationalism, a theory about what non-propositional intuitions are, where they come from, and how philosophers in fact (often contrary to their metaphilosophical musings) deploy them. Section 5 concludes with reflections on the significance of our claims for philosophical method.

What is the scope of our project? That is, of all the mental states that could be called "intuitions," which ones are we talking about? As Nado (2014) argues, the class of mental states called "intuition" is heterogeneous. So it's folly to generalize too broadly. We deal with this issue as follows. First, we restrict the scope of our theory to mental states had spontaneously in response to philosophical thought experiments, such as Gettier cases, which we treat here as paradigmatic of thought experiments. We use intuition types from other parts of psychology mainly for comparison and illustration, and we set many intuitions aside for now, such as mathematical intuitions. Second, even with this restriction, we acknowledge that some thought-experimental mental states plausibly called "intuitions" might not fit our theory. Accordingly, we present Interpretationalism as a theory of many (perhaps the majority) of the intuitions people have in response to thought experiments. It is an enlarged existential claim, not a universal one. This gives us a dialectical advantage over someone who would defend Mainstream Propositionalism, who must claim all thought-experimental intuitions are propositional; to win the dispute we only have to show some paradigmatic intuitions are not. Third, we acknowledge that how broadly our theory extends is in the end an empirical question; intuitions are psychological states and psychology is a matter for empirical investigation. Our theory applies at least to the examples we discuss here. But empirical evidence will have to determine how often and when the cognitive structures we detail in section 4 occur. In any case, since there are many philosophers to whom it has not even occurred that intuitions about philosophical thought experiments might not be propositional, our main contribution is to put Interpretationalism on the map.

\section{Mainstream Propositionalism}

Four popular claims conjoin to make Mainstream Propositionalism. Each comes in different forms, but we abstract from that variety in order to present evidence that the four claims are popular enough that their conjunction amounts to being a standard view.

(1) Intuitions are conscious. 
Koksvik (2011: 10) writes, "Having an intuition makes a particular contribution to the character of the overall experience of the person who is having it." Put simply, there is something it's like to intuit. This what-it's-likeness guides our interactions with philosophical claims and theories. When we reflect on some philosophical claim, our thinking may be punctuated by a peculiar phenomenology; suddenly, a claim appears in a certain light—-though we might not possess explicit, articulable reasons for why this should be so. Or we experience an alarm-like surge in phenomenology, a tug, push, or feeling of attraction or repulsion. Bealer (1998: 207) describes intuition as "a genuine kind of conscious episode" and calls intuitions "intellectual seemings" (208). ${ }^{4}$

\section{(2) Intuitions are spontaneous.}

Intuitions "flow spontaneously from the situations that engender them, rather than from any process of explicit reasoning" (Gopnik and Schwitzgebel 1998: 77). Though consciously entertaining a proposition or thought experiment may result in an intuition, intuitions themselves are not consciously formed. They are the conscious product of a non-conscious process. They cannot be formed via conscious inference from other conscious mental states. Nor can intuitions be directly summoned at will, though they can be indirectly facilitated by attention to appropriate stimuli (like Gettier cases). For this reason, intuitions are "phenomenologically basic; their inferential heritage is not introspectively available" (Kornblith 2002: 20). As far as first-person experience is concerned, intuitions spontaneously happen in the presence of certain inputs. ${ }^{5}$

\section{(3) Intuitions are non-theoretical.}

Imagine that you are seeing the Müller-Lyer figure for the first time.

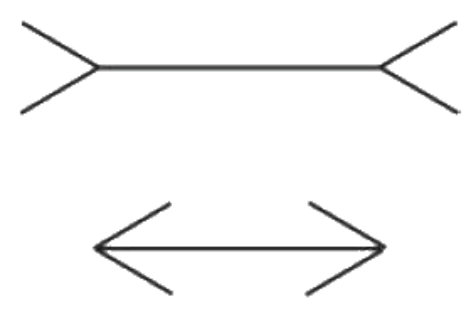

${ }^{4}$ The view that intuitions are phenomenally conscious is defended by Pollock (1974), Plantinga (1993), Bealer (1998, 1999), Pust (2000), Huemer $(2001,2007,2013)$, Koksvik (2011), Chudnoff (2011, 2013), and Bengson (2015). Goldman and Pust (1998), Goldman (2007), and Ludwig (2007) also intimate adherence to something like this claim. Even alleged deniers of intuitive phenomenology, Williamson (2007) and Sosa (2007), maintain that there is something it is like to intuit; however, they differ from many of the above authors in that they also maintain that this phenomenology is exhausted by what it's like to be consciously inclined to accept a proposition and what it's like to entertain a proposition, respectively.

${ }^{5}$ For more views that also suggest spontaneity, see Lycan (1988), Bealer (1998), Gopnik and Schwitzgebel (1998), Goldman and Pust (1998), Kornblith (2002), Nichols, Stich, and Weinberg (2003), Goldman (2007), Bengson (2015), and Taylor (2015). 
You are taken by the appearance of a longer line and a shorter one; you even form the belief that one line is longer. Shortly thereafter, you discover your experience was an illusion; neither line is longer than the other. A quick measurement assures you that your eyes have deceived you. But looking again, you find the unequal appearance remains! Despite believing otherwise, one line just seems longer; "the visual attraction to think them incongruent remains" (Sosa 2014: 41).

Thought-experimental intuitions seem to behave similarly. Like perceptual seemings, intuitions often put pressure on a subject's beliefs. And like perceptual seemings, intuitions are not subject to revision simply as the conclusion of a rational argument. ${ }^{6}$ Otherwise put, intuitions are non-theoretical.

Bealer (1998: 208) illustrates this point, writing, "Just try to diminish readily ... your intuition that your favorite Gettier example could occur." Intuitions, Bealer holds, just aren't rationally sensitive to our beliefs and desires. This claim has proved hugely influential. Pust (2000: 33), for instance, adds "[t]he appearance [in the Müller-Lyer case] . .. is impenetrable by belief ... in an analogous manner, our intellectual seemings or intuitions can diverge from our beliefs."

Bengson (2015: 721-22) unpacks the widely-endorsed analogy between perception and intuition in a way that highlights the intimate connection between non-theoreticality and spontaneity.

... one is not free to manage or get rid of [intuitions] in the way that one is, or at least sometimes is, free to manage or get rid of one's beliefs (e.g. by revisiting or resorting old evidence or by seeking new evidence). Similarly, one is not free to pick whether, what, and how to experience or intuit in the way that one is, or at least sometimes is, free to pick whether, what, and how to imagine, guess, hypothesize, or judge. When looking around at one's immediate environment, whether one has a visual experience, what the content of the experience that one has is, or whether the experience is clear and vivid, is not within one's conscious control. Likewise, when reflecting on a putative counterexample, thought experiment, or elementary logical or mathematical proposition, whether one has an intuition, what the content of the intuition that one has is, or whether the intuition is clear and vivid, is not within one's conscious control. 7,8

(4) Intuitions are propositional. [This is the one we reject.]

According to consensus, intuitions are propositional. Just as beliefs are beliefs that something is the case, intuiting essentially has propositional content.

The view that intuitions are propositional is taken for granted. The principal debate among theorists of intuition concerns what exactly intuiting that $p$ is, without much reflection on whether the "that $p$ " even belongs there. There is the doxastic

\footnotetext{
${ }^{6}$ It may be that they are revisable through a sort of practice, in which one attends to certain things and trains oneself in a certain way.

${ }^{7}$ Note that Bealer, Pust, and Bengson extend the claim of non-theoreticality to mathematical intuitions, about which we reserve judgment. For our purposes, it is enough that those scholars endorse the claim when it comes to thought-experimental intuitions.

${ }^{8}$ For more on non-theoreticality, see also Bealer (1998), Sosa (1998, 2007, 2014), Pust (2000), Goldman (2007), Ludwig (2007), Williamson (2007), Koksvik (2011), Chudnoff $(2011,2013)$, and Bengson (2015).
} 
view that intuiting involves believing, judging, or being inclined to believe or judge that $p$. Van Inwagen (1997: 309), for example, claims, “[o]ur 'intuitions' are simply our beliefs ..." Then there is the sui generis view according to which intuition is a distinct propositional attitude unto itself. Intuition, writes Bealer, is "a sui generis, irreducible ... propositional attitude" (1998: 207). For Cullison (2013: 33), the attitude of intuiting is "not analyzable in terms of the other mental phenomena." According to sui generis theorists, intuition essentially involves a conscious seeming, presentation, or appearance that $p$, in which a subject is made consciously aware of a proposition in a way that is epistemically favorable. Tucker (2010: 53) writes, "[t]he phenomenology of a seeming makes it feel as though the seeming is 'recommending' its propositional content as true or 'assuring' us of the content's truth." 10

In this debate, advocates of the doxastic view and advocates of the sui generis view, as noted, mostly take for granted that intuitions are always propositional and that their propositional contents are consciously accessible. To us, this illustrates how fierce debates often occur between two parties unreflectively in the grip of the same false dogma.

Thus, the purported properties of intuition are consciousness, spontaneity, non-theoreticality, and propositionality. Mainstream Propositionalism is the conjunction of the four claims attributing these properties. Importantly, Mainstream Propositionalists hold that intuiters are conscious of a specific proposition, as the above quotations confirm. This point is crucial to our refutation in the next section: intuiters, we hold, are conscious of something, but it's often not a specific proposition. Be that as it may, if we subtract claim (4) [that intuitions are propositional] from this cluster, we get a triad with which we agree: the intuitions we discuss are spontaneous, non-theoretical, and conscious (though their conscious aspect does not include consciousness of a proposition). Our positive view in section 4 accounts for each of these properties.

\section{Our Negative Project: Intuitions Are Not Propositional}

We give three arguments against Mainstream Propositionalism. All three point in the same direction: many intuitions do not have conscious propositional contents. This section is not merely negative, however, since its observations set the stage for our Interpretationalist theory.

\footnotetext{
${ }^{9}$ He adds, interestingly, "or perhaps, in some cases, the tendencies that make certain beliefs attractive to us." This latter portion could be interpreted along our lines.

10 For the view that intuition is a propositional attitude, see also van Inwagen (1997), Goldman and Pust (1998), Gopnik and Schwitzgbel (1998), Bealer (1998. 1999), BonJour (1998, 2001), Sosa (1998, 2007, 2014), Pust (2000), Huemer (2001, 2007, 2013), Kornblith (2002), Ludwig (2007), Tucker (2010), Koksvik (2011), Chudnoff (2011, 2013), Cullison (2013), and Bengson (2015). For the view that intuiting involves being aware of a proposition, see Tolhurst (1998), Bealer $(1998,1999)$, BonJour (1998, 2001), Hales (2000), Pust (2000), Huemer (2001, 2007, 2013), Tucker (2009), Chudnoff $(2011,2013)$, Lycan (2013), and Bengson (2015).
} 


\subsection{A Non-Propositional Phenomenology}

Let's reflect on our conscious mental states as we approach the critical moment of Gettier's classic piece. Imagine it's 1963, the year of publication. You begin reading with a firm conviction that justified true belief is knowledge. True, there are questions about each of the three focal terms in this standard analysis, but whatever waves rock the philosophical seas, knowledge and justified true belief ride them together. Or so you think.

But concern sneaks in as you read Gettier's set-up. "First...it is possible to be justified in believing a proposition that is in fact false" (121). "Secondly...if $S$ is justified in believing $\mathrm{P}$, and $\mathrm{P}$ entails $\mathrm{Q}$, and $\mathrm{S}$ deduces $\mathrm{Q}$ from $\mathrm{P}$...then $\mathrm{S}$ is justified in believing Q" (121). These points both feel familiar. But seeing them together, so simply put, is strangely unsettling.

Now comes the hammer.

... suppose that Smith has strong evidence for the following conjunctive proposition.

(d) Jones is the man who will get the job, and Jones has ten coins in his pocket.

...Proposition (d) entails:

(e) The man who will get the job has ten coins in his pocket.

... In this case, Smith is clearly justified in believing that (e) is true.

But imagine further that, unknown to Smith, he himself, not Jones, will get the job. And also unknown to Smith, he himself has ten coins in his pocket. Proposition

(e) is then true, though proposition (d), from which Smith inferred (e), is false. (122)

Something is amiss. You frantically read back over the case, just to make sure you understood everything. Yes... (d) is false, though justified ... yes... (d) entails (e) (but does anyone really have such a silly belief about 10 coins? does it matter? is (e) really justified) ...but yes... (e) is true! It appears that the conditions of justified true belief are satisfied, though you have a lingering suspicion that maybe they aren't really. And importantly, when you think of using "knowledge" to refer to Smith's belief (e), it feels off. That mental state-the something-feels-very-wrong internal feeling-is, on our view, the intuition.

Let's call this state "SFVW," for "something feels very wrong." In identifying SFVW with the Gettier intuition, we mean something specific. SFVW comes spontaneously in response to learning details of the Gettier case; it also appears independently of your background theory (it even feels contrary to it), so it is nontheoretical; SFVW also appears consciously. Finally, and importantly, SFVW gets you started on theory revision: it's the unpleasant feeling that motivates you to revise your earlier views in a way that, you hope, will make the unpleasant feeling go away. So SFVW has three of the four properties standardly thought characteristic of 
intuitions, and it is a starting point of theorizing; that's what we mean when we call it "intuition."

But, we think, SFVW is not propositional. Uneasy, something-is-wrong feelings are not specific enough to be attributed propositional content, which is a specific meaning. What would its proposition be? Is it that knowledge is not justified true belief? Is it that (e) wasn't really justified? Is it that Smith just doesn't know? Is it that a fourth condition is needed in the analysis? All of these possibilities (and maybe more) lurk in your mind in the moment after you have SFVW and before you revise your theory in a way you decide is right, which is an open-endedness you would not expect if the intuition had a clear, consciously-accessible propositional content.

SFVW has motivational force, pushing for you to look for a theoretical move that will alleviate the very wrong sense. After reflecting on your options, you judge, reluctantly, that Smith's belief ( $\mathrm{e}$ ) is not knowledge. But that judgment is not the spontaneous intuition, it is a product, in part, of the background beliefs you have that delineate the space of theoretical options before you. That is, your judgment is the product of interpreting the significance of SFVW, in light of your background beliefs. We might talk as if the intuition has the content that Smith's belief is not knowledge, but this loose talk conflates the intuition with its related follow-on judgment. Follow-on judgments often happen very quickly after intuitions, but they are still distinct.

Similar observations emerge from reflection on any number of thought experiments. Searle's (1980) “Chinese Room” elicits a sense of something's being missing, but it's not clear whether something is missing from the Chinese room or something is missing from our understanding of what occurs in it (Dennett 2013). Block's (1978) nation of China, Parfit's (1984) splitting cases, and many others will, on phenomenological reflection, yield similar results: the spontaneous, conscious intuition doesn't determine a precise proposition. Even further reflection may leave the intuition's significance unstable, oscillating until our related beliefs stabilize as well.

To summarize these points as sharply as possible, we assert the following. Many thought-experimental intuitions are positively or negatively valenced spontaneous, conscious, non-theoretical feelings that are directed at a cluster of ideas (broadly construed) and that motivate revising or maintaining beliefs one has about those ideas. A judgment, by way of contrast, is a conscious event in which a new belief is formed.

\subsection{Same Intuition, Varying Verbal Expression}

Now we face a fascinating puzzle. Experimental evidence is converging to show that there is a common intuition type among normal humans-across cultures, among "experts" and non-experts-in response to Gettier cases. There is, however, substantial variation in what people say about their Gettier intuitions. Philosophers, thinking Gettier intuitions have propositional content, say divergent things about that supposed content. And if you survey lay people about Gettier cases, whether or not they say the Gettiered agent "knows" is sensitive to other response choices offered in the survey (Cullen 2010). This is puzzling: if the Gettier intuition is 
common across people who read or hear Gettier cases, why are things people say in reporting that intuition so various and divergent?

We offer a solution to this puzzle. We agree with Machery et al. (2015) that there is, in human minds generally, a "universal core folk epistemology," and we think this core folk epistemology produces, in response to Gettier cases, tokens of a common intuition type. But, we maintain, intuitions of that type-Gettier intuitions-do not have consciously-accessible propositional content. The commonality of the intuition type explains why experimental results converge to the extent they do; but the fact that Gettier intuitions do not have consciously-accessible propositional content explains why people's expressions of those intuitions are so various: in grasping for verbal options to report Gettier intuitions, people come up with various things, since there is no conscious proposition affixed to the intuition to nail down what the verbal choice should be.

Here's the plan for this section (3.2). Step 1: we review evidence that there is a universal core folk epistemology. Step 2: we show how varied verbal reports of Gettier intuitions can be. Step 3: we say why our anti-propositionalist explanation of these data is better than Mainstream Propositionalism.

Step 1. Two questions are important. Do people across cultures respond to Gettier cases in similar ways? Do trained philosophers and lay people respond to Gettier cases in similar ways? If the answer to both is "yes," then it is fair to infer that normal humans generally have intuitions of a common type in response to Gettier cases. Both questions elicit controversy. Weinberg et al. (2001) famously claim that people from different cultures respond differently to Gettier cases, and Starmans and Friedman (2012) argue empirically that lay people differ from philosophers in their Gettier responses. However, the differences found by Weinberg et al. (i) aren't large and (ii) are contradicted by more recent, careful research. And the differences found by Starmans and Friedman (2012), while interesting, betray deeper similarities.

The case for commonality is clearer. Nagel et al. (2013a) tested lay subjects with a range of Gettier cases and found they were significantly less likely to attribute knowledge to Gettiered agents ${ }^{11}$ than to agents in matched True Belief cases, just as philosophers do. And in their response to Starmans and Friedman (2013), who criticize their work, Nagel et al. (2013b: 666) point out, "we all agree on a core point: both philosophers and laypeople take some Gettier cases to exemplify justified true belief without knowledge." And this is true: Starmans and Friedman (2012) did find that lay people denied knowledge to Gettier agents who had been duped by "apparent evidence." Thus, the controversy boils down to whether the overlap between lay responses and philosopher responses to Gettier cases is partial or total. The overlap is impressive in any case. A plausible construal of the evidence thus far, then, is that lay people and philosophers start from a common core folk epistemology, and if there are differences in responses, this is because philosophical training makes adjustments to a common folk epistemological system.

${ }^{11}$ By "Gettiered agent," we mean a character whose belief seems to count as justified and true, without seeming to count as knowledge. "Gettier cases" are situations described in vignettes, in which Gettiered agents and their beliefs are prominently featured. 
Machery et al. (2015), furthermore, survey individuals from several cultures (Brazil, India, Japan, and the USA) and find that responses to Gettier and other cases are similar across cultures. They present many subjects -245 in the final samplewith four cases: two Gettier-type cases, one case of clear knowledge, and one false belief case. The main dependent variables were responses to two knowledge probes. Their Knowledge 1 probe has the choices: "Yes, [s] he knows" and "No, [s] he doesn't know" (p. 5). Their Knowledge 2 probe has choices: "[Protagonist] knows that [relevant proposition]," and "[Protagonist] feels like [s] he knows that [relevant proposition] but [s] he doesn't actually know [this]" (p. 5).12 Two striking patterns emerge. First, across cultures, subjects deny knowledge in both probes significantly more to Gettiered agents than to agents in the clear knowledge case (effect sizes are substantial). Second, in response to the Knowledge 2 probe, rates of denial of knowledge across cultures are more similar between the Gettier cases and the False Belief case than between the Gettier cases and the Clear Knowledge case. The question then is this: why would people in such different cultures respond to bizarre and unfamiliar Gettier cases in more or less the same way? Machery et al. give a compelling answer: there is a universal core folk epistemology among humans (see section 4 for how this idea might be expanded upon).

If Machery et al. are right-we think they are at least close-it is natural to think that Gettier cases elicit intuitions of the same type ${ }^{13}$ across the majority of people who encounter those cases; these are intuitions that emerge from the core folk epistemology. In sum, the commonality of Gettier intuitions across lay people and philosophers, as well as across different cultures, explains why the tendency to deny knowledge to Gettiered agents is so widespread.

Step 2. Despite this commonality, there is still substantial variation in what people say in response to Gettier cases, in surveys and otherwise. Three kinds of divergence stand out.

First, Nagel et al. (2013a) observe that subjects who score lower on measures of empathy are less likely to indicate that Gettiered agents are justified. But many philosophers think that a verdict to the effect that the Gettiered agent is justified is part of the Gettier intuition. So if we were to ask, "is it part of the Gettier intuition that Gettiered agents are justified?" we would get divergent answers. Some would say "yes;" some "no." Furthermore, in informal discussion with other philosophers, we have noticed that some characterize the intuition as being partly about justification, while others only think it delivers a verdict on whether the Gettiered agent knows, which would leave the question of justification open. So people's reports (in surveys and otherwise) diverge in terms of whether they suggest Gettier intuitions have justification as part of their subject matter or not.

\footnotetext{
12 The purpose of the Knowledge 2 probe is to address the possibility that some subjects might read the Knowledge 1 probe as asking about felt knowledge from the point of view of the agent in the vignette, as opposed to asking about knowledge itself.

${ }^{13}$ When we say there are intuitions of the same type, we assume that intuitions can be classified by their etiological, phenomenological, and dispositional profiles and that to be of the same type is to belong to the same class so characterized. Obviously, we think it is a mistake to type intuitions according to their purported propositional content, as many philosophers would be inclined to do, since we don't think intuitions have such content.
} 
Second, Cullen (2010), in another empirical study, finds that the proportion of subjects who say the Gettiered agent "knows" is sensitive to whether the other option on the survey is "only believes" or is simply "doesn't know." Subjects presented with [knows vs. doesn't know] are more likely to pick knows for Gettiered agents than subjects presented with [knows vs. only believes]. Somehow, having only believes as an option attracts people away from knows. This, in our view, is probably because subjects are reluctant to deny epistemic credentials to Gettiered agents altogether, so they are more likely to pick knows when the only other option seems to deny those agents epistemic credentials entirely; having only believes as an option alleviates that pressure. Be that as it may, it is striking that context can cause people's responses to diverge even on the focal issue of knowledge.

Third, published metaphilosophy, which assumes Gettier intuitions have propositional content, has divergent accounts of what that content is. Williamson (2005: 5) accords Gettier intuitions counterfactually-structured content, of the form: "if someone had stood as described to a proposition, then whoever stood as described to a proposition would have had justified true belief without knowledge in respect of that proposition." Malmgren (2011: 281), responding to Williamson, argues instead that the content of Gettier intuitions is a modal proposition of possibility, which could be expressed, "It is possible that someone stands to $p$ as in the Gettier case (as described) and that she has a justified true belief that $p$ but does not know that $p . "$ And Ichikawa and Jarvis (2009) issue still another view. They claim that the content of the Gettier intuition is a proposition of necessity, roughly (see their paper for details): necessarily, if the Gettier vignette is completely true, then someone has a justified true belief but not knowledge. What can we conclude from all this? All three accounts are similar enough in spirit that they must be talking about the same intuition type. But they posit radically different propositional structures as the content of the intuition. Let us note one further thing: all of these philosophers engage in a substantial amount of reasoning to figure out what the content of the Gettier intuition is supposed to be; it is not as though the content is simply there to be read off.

Step 3. If Mainstream Propositionalism were right, all of this variation would be strange. According to that view, a person with an intuition is thereby consciously aware of some proposition (call it $q$ ): anyone with the same intuition is consciously aware of the same proposition, $q$, and this awareness is immediate (not reasoned toward), since intuitions are spontaneous. Thus, Mainstream Propositionalism suggests that people shouldn't have to think much about what the (supposed) contents of their intuitions in fact are, and people with the same intuitions should be able to agree on what the contents of those intuitions are supposed to be. But even philosophers have to think a lot about what the supposed proposition of an intuition might be, and often they disagree about it. Why should they have to work so hard to figure out a proposition of which they are supposed to be immediately aware? It is strange, from the perspective of Mainstream Propositionalism, that different philosophers characterize the contents of an apparently common intuition type so differently. If they all consciously intuit that $q$, why can't they agree on what $q$ is? Furthermore, the contents posited by Williamson, Malmgren, and Ichikawa and Jarvis are all rather baroque. Given that lay people have the same Gettier intuitions 
as philosophers, are we to say that lay people are consciously aware of propositions as complex as those described by the philosophers in question? In addition, the variation that Nagel et al. observe in whether people think Gettier beliefs are justified puts more pressure on Mainstream Propositionalism. Does $q$ include something about justification, or not? Finally, the sensitivity to alternate options on surveys, which Cullen observe, is puzzling for Mainstream Propositionalism, since that sensitivity appears to cause people to give different responses on the very focal issue of whether the Gettiered agents "know." Shouldn't q, for the Mainstream Propositionalist, at least include a clear verdict on knowledge, of which the person having the intuition would be conscious?

Such puzzles evaporate once our view is adopted. For us, the intuition is the vague but strong sense of something's being wrong with the ascription of knowledge to the Gettiered agents. That's it; no proposition. The commonality of this sense/intuition across people who have core folk epistemology (most people) accounts for the convergence in the experimental results that show people tend to deny Gettiered agents have knowledge: if something feels wrong about ascribing knowledge, it's natural to deny knowledge. But since the Gettier intuition doesn't have propositional structure, it doesn't include a clear verdict on questions like: is the Gettiered agent's belief justified? The lack of such verdicts explains the variation in observed Gettier reports, both among philosophers and lay people. The one thing that seems difficult for our account to explain is that philosophers seem so convinced that intuitions, including Gettier intuitions, are propositional. How could such intelligent people be so misled? But this is in fact no surprise for us. Appeal to propositional attitudes is so pervasive in philosophy-the approach often worksthat we expect it to be unreflectively overextended in certain domains. In fact, if you combine our view that intuitions are not propositional with the fact that philosophers have the false impression that they are, it is easy to explain why philosophers say intuitions have propositional content but then can't agree what that content is. In so saying, they just voice antecedent conviction; in not agreeing with one another, they accidentally reveal that that conviction is false.

Let's deal briefly with two apparent objections to the argument of this section. First objection: one might say that thought-experimental intuitions have propositional content, but that the intuiters are not conscious of that content. Though we find it dubious, we respond by taking no stand on this possible view, since our focus is on refuting Mainstream Propositionalism, which does imply consciousness of a proposition. But we add that even if intuitions did have nonconscious propositional content, much of what we say in sections 4 and 5 about the need for intuitions to be interpreted would still be true: since an intuition's conscious component would not be propositional, one would still need to engage in interpretation of that conscious component to figure out what the mooted nonconscious content is. Second objection: one might maintain that one can explain the data reviewed in this section by saying that the Gettier intuition's conscious content is simply that $\mathrm{x}$ 's belief is not knowledge (where $x$ is the Gettiered agent). ${ }^{14}$ We respond to this suggestion in three ways. (i) The suggestion will have a hard time

\footnotetext{
${ }^{14}$ Something like this would be the view of Goldman and Pust (1998).
} 
with Cullen's finding that people are less likely to deny knowledge, given certain options as opposed to others in a forced-choice paradigm. If the intuition were just a conscious denial of knowledge, we wouldn't expect such variability due to pragmatic features of survey design. (ii) If the Gettier intuition has that content and only that content, it is puzzling that philosophers disagree so much about the exact content of the intuition. If one has proposition $q$ as a part of a conscious mental state, one should be able to agree with others who have that same mental state about what the constituents of $q$ in fact are. Our view faces neither problem (i) nor (ii). Our response number (iii) comes at the end of the next section (3.3).

\subsection{Comparison with Linguistic Intuitions about Fiction}

Though our focus is on thought-experimental intuitions, it is worth asking whether similar things can be said about other intuition types. The brain often uses the same psychological structures for various purposes. So if intuitions of a certain formspontaneous, conscious, non-theoretical, and non-propositional-are found to occur outside thought-experimental mental processes, that fact increases the likelihood that intuitions of that form occur inside thought-experimental processes too. ${ }^{15}$

Here we argue that linguistic intuitions about fictional sentences are nonpropositional. Consider this as one step in a larger exploration of the terrain of nonpropositional intuitions.

Consider two sentences about Hermione Granger, the clever wizard-intraining at Hogwarts:

(HG1) Hermione can cast spells.

(HG2) Hermione has 42 fingers.

If you know even a bit about Harry Potter, you probably just had intuitions. HG1 seems right (in some way), and HG2 seems wrong (in some way). Let's call the intuition types had in response to these sentences I1 and I2, respectively. It's highly likely that, as psychological kinds, I1 and I2 have roughly the same characteristics across speakers of English who are familiar with Harry Potter: the language is common (English); the stories are familiar; the capacity to process fiction is a general human trait; so intuitions in response to sentences describing familiar figures, like Hermione, shouldn't differ much from person to person. I1 is a sort of internal, conscious $u h-h u h$; I2 is an internal, conscious nuh-uh.

Now, toward reductio, let's assume that Propositionalism-f (that is, Mainstream Propositionalism suitably modified to be about intuitions about fictional discourse) is true of I1 and I2: people who have I1, on this view, are conscious of a proposition, as are people who have I2. If this is correct, people should report their tokenings of I1 and I2 using equivalent or at least almost equivalent propositional complements; at the very least, their reports should be consistent with

15 To make a similar point, it is scientifically desirable to unify theories as much as possible (Friedman 1974), so unifying thought-experimental intuitions with others-provided it seems empirically reasonable-should count in favor of any theory of intuition. 
one another. If one English speaker reports I1 as that $p$, another should report a similar content or at least a content that coheres with $p$. But this is not what we are likely to find. ${ }^{16}$ One person will say, "HG1 is true. She can cast spells." But another will say, "Yeah, I know HG1 isn't true because it's fiction, but it gets things right."

Both speakers are trying to report the same "uh-huh" intuition to HG1. But they differ in what they say due to different background views about whether fictional sentences can be true. The two speakers in fact contradict one another, despite reporting the same "uh-huh" intuition. The first speaker says HG1 is true, while the second says it's not true (though still somehow right). So not only is the same intuition type ("uh-huh") reported in ways that are non-equivalent; it is even reported in ways that contradict. This, we think, would not happen if tokenings of I1 came with conscious propositional content. So Propositionalism-f is not true of I1 after all; a parallel argument can be run for I2. But I1 and I2 are conscious, spontaneous, and non-theoretical (check your phenomenology), so the thing to reject is the element of Propositionalism-f that says I 1 and I 2 are propositional. This argument generalizes to most intuitions about fictional sentences.

The argument just given puts defenders of Propositionalism-f on their heels. They might say that I1 simply has the content that HG1 is true and I2 the content that HG2 is false; they would then claim that people who say otherwise are just letting their verbal reports of an otherwise clear intuition be obfuscated by a pet theory of fictional semantics. But this response is straining. A speaker who says "I know HG1 isn't true ..." is unlikely to have had a conscious intuition that HG1 is true: when this speaker verbalizes that HG1 is not true, she does not take herself to be saying something that contradicts a consciously intuited proposition. Rather, her saying "Yeah, I know HG1 isn't true because it's fiction, but it gets things right" is a fumbling attempt at expressing that something feels right about HG1.

This murkiness about what to say about fictional sentences infects the philosophical literature on fiction as well. And it does so in a way that further suggests that intuitions like I1 and I2 don't come with conscious propositional contents. There is, as one would expect, widespread agreement that sentences along the lines of HG1 are in some way correct and that sentences along the lines of HG2 are in some way not. But in what ways are they "correct" or "incorrect"? Here the consensus stops. Lewis (1978) regards sentences like "Sherlock Holmes lived in Baker Street" as true and having an implicit "In fiction $f$..." operator (hence his title: "Truth in Fiction"), and he regards sentences like "Sherlock Holmes has three nostrils" as false (operator or no). Accordingly, he gives a theory of the meaning of fictional sentences according to which they can come out as true or false; for him, the contents of fictional sentences are complex counterfactuals. But Walton (1990), in a rather different theory, characterizes such sentences in terms of fictionality, a term of art that does not mean straightforward truth. HG1 would, for him, count as fictional, and HG2 would count as not fictional. He would cash this out, roughly, by saying that the Harry Potter game of make-believe prescribes imagining the proposition expressed by HG1, while it does not prescribe imagining the proposition

${ }^{16}$ We grant, of course, the question is empirical, but find it highly plausible that the data would work out as we suggest. 
HG2 expresses. Importantly, for Walton, HG1 and HG2 both express literally false propositions, though one is fictional and the other is not. Taylor (2000), on the other hand, holds a view strikingly at odds with both Walton's and Lewis'. Taylor, a dyedin-the-wool referentialist, holds that sentences with empty names, like "Hermione," simply do not assert propositions, since a syntactically well-formed sentence still doesn't give you a proposition if some of its constituents are empty. Rather, for Taylor, HG1 would express a "proposition-in-waiting" or an unsaturated "propositional scheme." For him, sentences with empty names can't be true or false; they have no semantic value whatsoever. Taylor then argues that, though such sentences assert nothing, they manage to be pseudo-assertions and some of what is pseudo-asserted can be propositional and true. ${ }^{17}$

Lewis, Walton, and Taylor, as normal readers of fiction and normal speakers of English, presumably have the same intuitions about correct or incorrect fictional sentences as anyone else. These intuitions are their data as theorists and are the reason they're not talking past each other. But note that there is no exact proposition that the three theorists even could share as an "intuitive" starting point. Notice, for example, how cautious and unspecific Taylor is about what the intuitions even are: "I acknowledge the deference due to the widely shared intuition that one who utters any of (1)-(3) may speak truly, while one who utters any of (4)-(6) may speak falsely" (18). We think this caution ("may speak truly") is appropriate. If you were to press Lewis, Walton, and Taylor with the question, "What is the content of I1?", you would get very different responses, along the following lines:

Lewis would say: "I1 has the content that HG1 is true." Walton would say: "I1 has the content that HG1 is fictional."

Taylor would say: "I1 has the content that HG1 is pragmatically appropriate."

What causes this divergence? We have a simple explanation. I1 has no propositional content, so if theorists were confronted with saying what its content was, they would be forced to make something up, which they would do partly by consulting background beliefs. I1 conveys the sense of something's being right about HG1, but what exactly that is must be worked out by interpretation (what's causing it to feel right?) in consultation with one's evolving set of background beliefs.

To return to the main thread of this essay, thought-experimental intuitions appear to have relatives in fictional-discourse intuitions: both kinds of intuition are spontaneous, conscious, non-theoretical, and non-propositional. Is this coincidence a coincidence? We think not. Thought experiments, in the end, are miniature fictions. So thought-experimental intuitions should have the same characteristics as intuitions about fiction generally. Gettier's case about Smith is purely fictional. There is no Smith; correspondingly, there is no man with such a belief about ten coins. Now take the fictional sentence: "Smith's belief about ten coins is true." One intuits that there is something right about this sentence, but it is hard to make out exactly

\footnotetext{
${ }^{17}$ Taylor focuses on cases that mix fictional names with claims about reality, such as "Santa Claus does not exist" or "Santa Claus isn't coming tonight." But much of what he says about such mixed sentences can carry over to purely fictional sentences as well.
} 
what the supposed content of this intuition should even be, given that there is no Smith and no actual belief. Your intuition pushes you to try to make sense of the sentence, but it cannot be more specific than that.

Let's return now to the objection to our thinking that we discussed at the end of the last section (3.2). That objection attempted to make sense of the data that motivate us by saying that the content of Gettier intuition just is that x's belief is not knowledge (where $x$ is the Gettiered agent). Our response (iii) to this is as follows: since, for any Gettiered $x, x$ is a non-existent fictional character, it is entirely unclear exactly what the mooted proposition is even supposed to be. ${ }^{18}$ That lack of clarity is made palpable by the divergences between Lewis, Walton, and Taylor on the semantics of sentences with fictional names. And if it's not clear what the proposition is supposed to be, it's unlikely that any layperson or philosopher has spontaneous conscious access to that mooted proposition as part of an intuition. But it is an entailment of Mainstream Propositionalism that people should have spontaneous conscious access to a proposition; so much the worse for Mainstream Propositionalism. ${ }^{19}$

\section{Our Positive Proposal: Interpreting Intuitions}

We asserted earlier: many thought-experimental intuitions are positively or negatively valenced spontaneous, conscious, non-theoretical feelings that are directed at a cluster of ideas (broadly construed) and that motivate revising or maintaining beliefs one has about those ideas. Where might such mental states come from?

Much information in our brains is buried in stores of sub-doxastic mental systems. This includes information about the biological world, the physical world, contagion, threats, people's minds and social relations, language, and even-it seems - the structure of knowledge. ${ }^{20}$ "Sub-doxastic" means that much of this information, though poised to guide various behaviors (like freezing or avoiding in response to threats), is not poised for conscious, verbal expression. People "know" things about biological kinds that they can't consciously express-for example, that a single organism cannot belong to two different kinds at the same "level" (no elm-

\footnotetext{
18 This, by the way, is why the Ichikawa and Jarvis (2009) theory comes out as complicated as it does.

${ }^{19}$ At the risk of belaboring the point, we can put this response into the form of a dilemma. Any proposition complex enough to be identified with truth conditions for a fictional sentence would be too complex to be borne in mind spontaneously and consciously (just look at Lewis' final analysis!). So either you accord the intuitions in question genuine propositional content or you don't. If you do, that content is too complex to be conscious. If you don't, you don't. Either way, Mainstream Propositionalism loses. As it happens, Ichikawa and Jarvis (2009: fn. 14) express some reservations as to whether the thought-experimental processes they discuss are all conscious, so it seems they might go with the first horn of the dilemma.

20 [References.] Folk biology: Medin and Atran (1999). Folk physics: McCloskey (1983); Baillargeon (2002); Proffitt and Kaiser (2006). Contagion system: Rozin et al. (1986); Springer and Belk (1994). Fear and threats: LeDoux (1996). Mindreading / folk psychology: Baron-Cohen (1995); Flavell (1999); Nichols and Stich (2003); Goldman (2006). Language: Chomsky (1965, 1986, 1995); Pinker (1994). Core folk epistemology: Machery et al. (2015).
} 
beeches). ${ }^{21}$ People often don't even realize that they have such sub-doxastic information, since much of it guides inference and behavior without ever being coded as explicit conscious principles. We propose that the core folk epistemology identified by Machery et al. (2015) is also a largely sub-doxastic information store, as are many of the information stores probed by philosophical thought experiments, which are, as Dennett (2013) aptly puts it, "intuition pumps."

It is useful that not all information in the brain is conscious; if it were otherwise, consciousness would be swamped and unable to support decisionmaking. But the downside of this mostly useful arrangement is that it's difficult to make sub-doxastic information conscious and explicit. The information humans have about object statics, for example, enables us to stack things (Povinelli 2000, Baillargeon 2002); it's not there to help us verbalize axioms of object statics. Your sub-doxastic fear system (another example) may tell your consciousness that something is a threat-you feel a fright at it-without revealing the information it uses to categorize something as a threat. The path from the sub-doxastic storage up to conscious verbal formulation is rocky.

We have, however, a cognitive tool for digging information out. We can voluntarily imagine situations and then see whether our sub-doxastic systems produce an error or no-error signal of some sort-or any other reaction. Subdoxastic systems produce fast reactions to events in the world. But we can also imagine events in order to get similar kinds of reaction. Since the world to which sub-doxastic systems react largely arrives in a sensory way, imaginings, which often have sensory constituents (mental imagery), can help get those reactions. These reactions are imagination-induced intuitions. What is imagined can be chosen voluntarily, but the intuition the imagining induces is not subject voluntary control and is often not even anticipated (that's often the point): it's spontaneous. And the intuition is non-theoretical in that, instead of conforming to antecedent conscious thought, it conforms to sub-doxastic information. Finally, though the intuition is conscious, though the sub-doxastic information generating it is not.

Our goal is to apply this framework to thought-experimental intuitions. But first, let's again observe a similar process in the linguistic case, just to have a parallel example.

Suppose we consciously endorsed a grammatical rule that a grade school teacher might have taught us: "nouns are pluralized whenever they refer to numerically more than one object, but not otherwise." But now imagine the following (ungrammatical) strings of words:

*He ate zero piece of cake.

* On her plate was 0.5 piece of cake.

*They shared 1.0 piece of cake.

${ }^{21}$ This is a cross-culturally shared "axiom" of folk biology (Atran et al. 1997). We put "know" here in scare quotes to refer to implicit awareness of information that helps guide behavior, even if that awareness doesn't rise to the level of knowledge in a strict sense. 
All three strings comport with the conscious principle just mentioned, since "piece" in no case refers to numerically more than one. But they all elicit an error signal from the sub-doxastic language system, since the more fundamental sub-doxastic rules of language (Chomsky's 1986 "I-Language") differ from the consciously endorsed ones. This error signal is an intuition: spontaneous, conscious, and nontheoretical (in the sense that it isn't governed by one's consciously endorsed grammar). Conscious thought sends the imagined examples down to the subdoxastic system, which processes them unconsciously and then belches up an intuition to consciousness. Systematizing such intuitions as evidence for a theory of the "language acquisition device" is the grand project Chomsky $(1957,1965)$ initiated.

When a sub-doxastic system produces an error signal (or other signal), one is often at a loss as to which element of one's imagined example caused that error signal (or other signal)..$^{22}$ Sometimes it's obvious, as when I imagine a stone falling upward. But sometimes it's not at all obvious, as in the Gettier cases. Either way, one must consciously interpret the error or no-error signal in light of other beliefs in order to understand its significance for the imagined example. Other beliefs about the imagined situation often give guidance as to the source of the error. But different belief sets will assign different meanings to error or no-error signals of the same type, as we saw with differing interpretations of sentences with fictional names.

Turning now explicitly to philosophical thought experiments, we arrive at the following view. The original Gettier intuition is elicited by imagining the Smith "10 coins" example, along with imagining applying the term "knowledge" to Smith's belief, and then sending that combined imagined case down to one's sub-doxastic conception of knowledge / core folk epistemology. The intuition in response to the Gettier case is the error signal that the sub-doxastic system spontaneously belches up. (We think this same process, mutatis mutandis, will turn out to be characteristic of much philosophical thought experimentation.)

It is up to one's subsequent interpretation to make sense of this error signal (or whatever the response is) and formulate a judgment. One might judge that justified true belief isn't sufficient for knowledge. Or one might judge that Smith's belief wasn't really justified. Different background beliefs (or different levels of empathy) yield different interpretations of the same error signal/intuition.

We sketch the mental processing of Gettier's thought experiment below, where the dashed line represents the muddy boundary between conscious and unconscious processing and where arrows trace the order of processing:

\footnotetext{
22 We focus here mainly on error signals mostly for reasons of space and because those seem to include the intuitions prompted by Gettier cases, which are our running examples. We think, however, that the broad structure of our account could apply to many "positive" intuitions as well.
} 


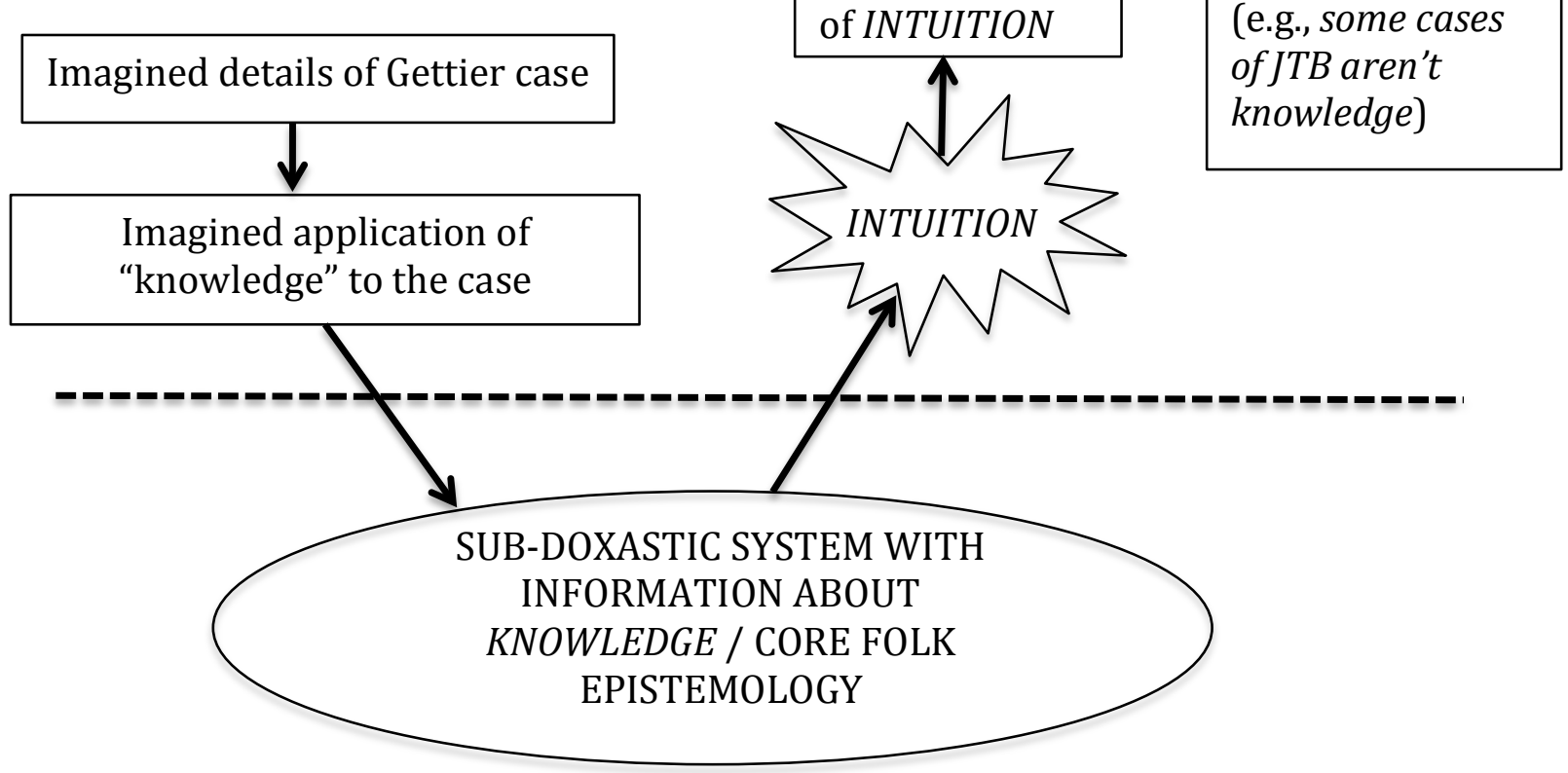

Conscious thought, which first considers the case, begins in the dark about what is or isn't "intuitively" problematic about it; the detailed processing first happens in sub-doxastic systems; consciousness then ponders significant features of the thought experimental case to which the intuition is a response. If all goes well, it comes up with a reasonable interpretation of the case, in light of the intuitive response. ${ }^{23}$

How does the information in sub-doxastic systems get there? The answer is various. Some information in sub-doxastic systems may be innate (this is Chomsky's view of the language organ); other information may be what McCauley (2011) calls "maturationally natural" (it occurs as a reliable product of a maturing person's interaction with normal environmental inputs); and some might be acquired from experiences that manage to influence how low-level processes work. This last possibility is easily overlooked: the fact that some information is acquired through experience/learning does not entail that it is conscious or easily revisable. As Ernst Mach writes:

Everything which we observe imprints itself uncomprehended and unanalyzed on our percepts and ideas, which then, in their turn, mimic the process of nature in their most general and striking features. In these accumulated experiences we posses a treasure-store, which is ever close at hand, and of which only the smallest portion is embodied in clear articulate thought. The circumstance that it is easier to resort to these experiences than it is to nature herself, and that they are, notwithstanding this, free, in the sense indicated, from subjectivity, invests them with high value. (1883/1960: 36)

\footnotetext{
${ }^{23}$ This process may of course be iterative, with repeated cycles of slightly varied examples being sent down to the sub-doxastic systems. Dennett (2013) calls this "turning the knobs."
} 
Gendler (1998: 415) interprets this passage as saying that much of the valuable and reliable information we have is in our minds "not organized under any theoretical framework." We endorse Gendler's interpretation and note that it fits well with the aims of this paper. Intuitions issue from the non-theoretical "treasure-store" of subdoxastic information, when that store is prompted by imaginings, including thought experiments.

In sum, intuitions are spontaneous, conscious products of sub-doxastic, nontheoretical systems, which can be elicited by way of imagining. This appears to be so for intuitions in response to many sorts of imagined situation, including especially those portrayed in philosophical thought experiments.

How does the conscious interpretation of intuitions work?

There is no single answer to this question, since interpretation is holistic. But let's sketch how it goes sometimes. When one has an intuition, one forms a belief that one had an experience with a certain phenomenology. Call this the experience belief. One then forms linking beliefs that link the experience belief, which is about the intuition, to the body of theoretical beliefs under consideration. A linking belief could be: "If theoretical propositions $p_{1}, \ldots, p_{n}$ were true, then the thought experimental case wouldn't have prompted the negative intuition it did." This linking belief, in conjunction with the experience belief, prompts one to reject at least one of the theoretical propositions $p_{1}, \ldots, p_{n}$. But which one? Here one must use other beliefs to help figure out which of $p_{1}, \ldots, p_{n}$ is most worth rejecting. One might then judge that $p_{3}$ is false. If one does, one might carelessly say, "I have an intuition that $p_{3}$ is false." But this talk, though tempting, conflates the intuition with the follow-on judgment. We should not attribute $p_{3}$ to the intuition because (i) the denial of $p_{3}$ is a theoretical belief that has its significance partly in virtue of other surrounding theoretical beliefs and (ii) one may just as well have come to reject $p_{2}$ or $p_{4}$ instead of $p_{3}$ in light of the intuition and experience belief, if one had had somewhat different background beliefs. ${ }^{24}$ So linking the intuition specifically to denial that $p_{3}$ is true, even if that's the judgment one comes to have, is a mistake.

This concludes our positive theory of interpreting intuitions, which, once grasped, is fairly simple. For convenience, we restate its basic components here:

1. Thought experiments are represented in conscious imaginative acts.

2. Those imaginative acts trigger further processing in sub-doxastic systems.

3. As a result of that processing, which is unconscious, the sub-doxastic systems bring about an intuition in consciousness.

4. That intuition is non-propositional, though it often has a positive or negative valence.

5. Conscious thought interprets the intuition in light of other beliefs in a way that yields a propositional judgment. ${ }^{25}$

\footnotetext{
${ }^{24}$ Here the spectre of the Quine-Duhem problem hovers over the interpretation of thoughtexperimental intuitions.

${ }_{25}$ Points 4. and 5. here correspond to the two "stages" of intuition and judgment mentioned in the introduction.
} 
We think this account covers a wide range of thought-experimental intuitions, though perhaps not all. It is an empirical question in the end how far the account extends. Interpretationalism has the virtue of comporting well with both phenomenology and psychology, and it preserves most of what we want to say about the psychology of intuitions: they are spontaneous, conscious, and nontheoretical. Our only major revision to the psychological picture of intuitions is in giving up propositionality.

\section{Conclusion: The Use of Intuition in Philosophy}

We have given reasons for thinking that many thought-experimental intuitions, including especially the ever-fascinating Gettier intuition, do not have consciouslyaccessible propositional contents. Mainstream Propositionalism is false. The phenomenology of having intuitions in response to important thought experiments does not comport with that view. The view also stumbles at addressing the puzzle of why people with the same intuition type say strikingly different things in expressing their intuition tokens. And the psychology of related intuitions about fictional sentences appears not to be propositional either.

A better view is on offer: Interpretationalism. This view avoids the problems of Mainstream Propositionalism and sits well with contemporary cognitive science. On this view, thought-experimental intuitions are conscious states that occur in relation to imagined examples and philosophical positions that pertain to those examples; such intuitions are non-propositional, so their philosophical significance in propositional terms needs to be worked out through a process of interpretation in conjunction with background beliefs. One cannot simply "read off" propositional content from a thought-experimental intuition. The appearance to the contrary is largely the product (i) of confusing the intuition with follow-on propositional judgments (which may occur in quick succession) ${ }^{26}$ and (ii) of wishful thinking.

What wishful thinking do we mean? Doing philosophy would be a neater, more straightforward process if our thought-experimental intuitions had clear, conscious propositional contents. Propositions would be convenient places to begin theorizing, even if we treated them as defeasible. Propositions, on many construals, are structured in a way that can serve as the basis for logical derivation, a process at which most philosophers have some skill. We thus suspect, though few would openly endorse it, that many philosophers are still quietly tempted by the lull of an image of philosophy in which intuited propositions plus logical inference forms straightforwardly justify philosophical theories. But that's just not how it works. Rather, intuitions cast shade or sunlight over certain regions of intellectual space,

\footnotetext{
${ }^{26}$ One more point on terminology: even if Mainstream Propositionalists wanted to stipulate that they use the word "intuition" to refer to judgments, they would still need a word for the things we call intuition, which are non-propositional and no doubt exist; also, they would have to give up the nontheoreticality of intuition, which is supposed to be its chief epistemic virtue, since the judgments that issue from thought experiments are theoretically loaded.
} 
inviting us to look further. The resulting philosophical work we must do is far more difficult than the Mainstream Propositionalist picture would have us think. But it is also, in the end, much more creative and rewarding.

\section{Acknowledgements}

We would like to thank the audience at the Belief and Intuition workshop held at the University of Antwerp in May 2016, at which Neil Van Leeuwen presented this joint work. We would also like to thank, in particular, James Andow, John Bengson, and Stephen Stich (who was entirely unconvinced by our view) for stimulating exchanges. Due to time pressures on submitting, we were unable to incorporate many of their important points and concerns into this essay, but we hope to address them in the future. This work was supported in part by the Marie Skłodowska-Curie Fellowship that Neil Van Leeuwen received from the European Commission [call identifier: H2020-MSCA-IF-2014; contract number: 659912].

\section{References}

Atran, S., Estin, P., Coley, J., and Medin, D. (1997) "Generic Species and Basic Levels: Essence and Appearance in Folk Biology," Journal of Ethnobiology 17(1): 1743.

Baillargeon, R. (2002) "The Acquisition of Physical Knowledge in Infancy: A Summary in Eight Lessons," Blackwell Handbook of Childhood Cognitive Development, ed. U. Goswami, 47-83.

Baron-Cohen, S. (1995) Mindblindness: An Essay on Autism and Theory of Mind, Cambridge, MA: MIT Press.

Bealer, G. (1998) "Intuition and the Autonomy of Philosophy," in M. DePaul and W. Ramsey (eds.) Rethinking Intuitions: The Psychology of Intuition and Its Role in Philosophical Inquiry, Rowman \& Littlefield, pp. 201-239.

Bealer, G. (1999) "A Theory of the A Priori," Philosophical Perspectives 13, pp. 29-55. Bengson, J. (2015) “The Intellectual Given," Mind 124(495), pp. 707-760.

Block, N. (1978) "Troubles with Functionalism," Minnesota Studies in the Philosophy of Science 9: 261-325.

BonJour, L. (1998) In Defense of Pure Reason, Cambridge: Cambridge University Press.

BonJour, L. (2001) "Precis to In Defense of Pure Reason," Philosophy and Phenomenological Research 63(3), pp.625-631.

Chomsky, N. (1957) Syntactic Structures, Berlin: Walter de Gruyter.

Chomsky, N. (1965) Aspects of a Theory of Syntax, Cambridge, MA: MIT Press.

Chomsky, N. (1986) Knowledge of Language, Westport, CT: Praeger Publishers.

Chomsky, N. (1995) “Language and Nature," Mind 104(413): 1-61.

Chudnoff, E. (2011) "What Intuitions are Like," Philosophy and Phenomenological Research 82(3), pp. 625-654.

Chudnoff, E. (2013) Intuitions, Oxford: Oxford University Press..

Cullen, S. (2010) "Survey-Driven Romanticism," Review of Philosophy and Psychology 1(2): 275-296. 
Cullison, A. (2013) "Seemings and Semantics," in C. Tucker (ed) Seemings and Justification: New Essays on Dogmatism and Phenomenal Conservatism. Oxford, pp. 33-51.

Dennett, D. C. (1987) The Intentional Stance, Cambridge, MA: MIT Press.

Dennett, D. C. (2013) Intuition Pumps and Other Tools for Thinking, W. W. Norton.

Flavell, J. H. (1999) “Cognitive Development: Children's Knowledge About the Mind," Annual Review of Psychology 50: 21-45.

Friedman, M. (1974) "Explanation and Scientific Understanding," Journal of Philosophy 71(1): 5-19.

Gendler, T. (1998) "Galileo and the Indispensability of Scientific Thought Experiment," British Journal for the Philosophy of Science 49(3): 397-424.

Gettier, E. "Is Justified True Belief Knowledge?," Analysis 23, pp. 121-123.

Goldman, A. (2006) Simulating Minds: The Philosophy, Psychology, and Neuroscience of Mindreading, Oxford: Oxford University Press.

Goldman, A. (2007) "Philosophical Intuitions: Their Target, their Source, and their Epistemic Status," Grazer Philosophische Studien 74(1), pp. 1-26.

Goldman, A. and Pust, J. (1998) "Philosophical Theory and Intuitional Evidence," in M. DePaul and W. Ramsey (eds.) Rethinking Intuitions: The Psychology of Intuition and Its Role in Philosophical Inquiry, Rowman \& Littlefield, pp. 179198.

Gopnik, A. and Schwitzgebel, E. (1998) "Whose Concepts Are They, Anyway? The Role of Philosophical Intuition in Empirical Psychology," in M. DePaul and W. Ramsey (eds.) Rethinking Intuitions: The Psychology of Intuition and Its Role in Philosophical Inquiry, Rowman \& Littlefield, pp. 76-91.

Hales, S. (2000) “The Problem of Intuition," American Philosophical Quarterly 37, pp. 125-147.

Huemer, M. (2001) Skepticism and the Veil of Perception, Lanham, MD: Rowman and Littlefield.

Huemer, M. (2007) "Compassionate Phenomenal Conservatism," Philosophy and Phenomenological Research 74(1), pp. 30-55.

Huemer, M. (2013) "Phenomenal Conservatism Uber Alles," in C. Tucker (ed.) Seemings and Justification: New Essays on Dogmatism and Phenomenal Conservatism, Oxford University Press, pp. 328-350.

Ichikawa, J and Jarvis, B. (2009) "Thought-experiment intuitions and truth in fiction," Philosophical Studies 142, pp. 221-246.

Koksvik, O. (2011) "Intuition," Diss. Australian National University.

Kornblith, H. (2002) Knowledge and Its Place in Nature, Oxford: Oxford University Press.

LeDoux, J. E. (1996) The Emotional Brain: The Mysterious Underpinnings of Emotional Life, New York, NY: Touchstone / Simon \& Schuster.

Lewis, D. K. (1978) "Truth in Fiction," American Philosophical Quarterly 15(1), pp. $37-46$.

Lewis, D. K. (1983) Philosophical Papers: Volume I, Oxford: Oxford University Press. Ludwig, K. (2007) "The Epistemology of Thought Experiments: First Person versus Third Person Approaches," Midwest Studies in Philosophy 31, pp. 128-159. 
Lycan, W. (1988) Judgment and Justification, Cambridge: Cambridge University Press.

Lycan, W. (2013) "Phenomenal Conservatism and the Principle of Credulity," in C. Tucker (ed.) Seemings and Justification: New Essays on Dogmatism and Phenomenal Conservatism, Oxford University Press, pp. 293-305.

Mach, E. (1883/1960) "On Thought Experiments," in Knowledge and Error, sixth edition, trans. T. McCormack and P. Foulkes, Dortrecht: Reidel, pp. 134-147.

Machery, E., Stich, S., Rose, D., Chatterjee, A., Karasawa, K., Struchiner, N., Sirker, S., Usui, N., and Hashimoto, T. (2015) “Gettier Across Cultures," Nous (online) doi: $10.1111 /$ nous. 12110

Malmgren, A. (2011) "Rationalism and the Content of Intuitive Judgments," Mind 120(478): 263-327.

McCauley, R. N. (2011) Why Religion is Natural and Science is Not, Oxford: Oxford University Press.

McCloskey, M. (1983) “Intuitive Physics,” Scientific American 248(4), pp. 122-130.

Medin, D. L. and Atran, S. (1999) Folkbiology, Cambridge, MA: MIT Press.

Nado, J. (2014) “Why Intuition?" Philosophy and Phenomenological Research 86(1): $15-41$.

Nagel, J., San Juan, V., and Mar, R. (2013a) “Lay denial of knowledge for justified true beliefs," Cognition 129(3): 652-661.

Nagel, J., Mar, R., and San Juan, V. (2013b) "Authentic Gettier Cases: A Reply to Starmans and Friedman," Cognition 129(3): 666-669.

Nichols, S. and Stich, S. (2003) Mindreading, Oxford University Press, Oxford.

Nichols, S., Stich, S., and Weinberg, W. (2003) "Metaskepticism: Meditations in Ethno-Epistemology," in S. Luper (ed.), The Skeptics, Burlington, VA: Ashgate, pp. 227-247.

Parfit, D. (1984) Reasons and Persons, Oxford: Oxford University Press.

Pinker, S. (1994) The Language Instinct: How the Mind Creates Language, New York, NY: Harper Perennial Modern Classics.

Plantinga, A. (1993) Warrant and Proper Function, Oxford: Oxford University Press.

Pollock, J. (1974) Knowledge and Justification, Princeton, NJ: Princeton University Press.

Povinelli, D. J. (2000) Folk Physics for Apes: The Chimpanzee's Theory of How the World Works, Oxford: Oxford University Press.

Proffitt, D. R. and Kaiser, M. K. (2006) "Intuitive Physics," Encyclopedia of Cognitive Science.

Pust, J. (2000) Intuitions as Evidence, Routledge.

Rozin, P., Hammer, L., Oster, H., Horowitz, T., Marmora, V. (1986) “The child's conception of food: differentiation of categories of rejected substances in the 16 months to 5 year age ranges," Appetite 7(2): 141-151.

Searle, J. R. (1980) “Minds, Brains, and Programs," Behavioral and Brain Sciences 3(3): 417-457.

Sosa, E. (1998) "Minimal Intuition," in M. DePaul and W. Ramsey (eds.) Rethinking Intuitions: The Psychology of Intuition and Its Role in Philosophical Inquiry, Rowman \& Littlefield, pp. 257-269. 
Sosa, E. (2007) "Intuitions: Their Nature and Epistemic Efficacy," Grazer Philosophische Studien 74(1), pp. 51-67.

Sosa, E. (2014) "Intuitions: Their Nature and Probative Value," in A. Booth and D. Rowbottom (eds.), Intuitions, Oxford: Oxford University Press, pp.36-49.

Springer, K. and Belk, A. (1994) "The Role of Physical Contact in Early Contamination Sensitivity," Developmental Psychology 30(6): 864-868.

Starmans, C. and Friedman, O. (2012) "The Folk Conception of Knowledge," Cognition 124(3): 272-283.

Starmans, C. and Friedman, O. (2013) “Taking 'Know' for an Answer: a Reply to Nagel, San Juan, and Mar," Cognition 129(3): 662-665.

Taylor, K. (2000) "Emptiness without Compromise: A Referentialist Semantics for Empty Names," in A. Everett and T. Hofweber (eds.), Empty Names, Fiction, and the Puzzles of Non-Existence, Stanford, CA: CSLI Publications, pp. 17-36.

Taylor, S. A. (2015) "What Seemings Seem to Be," Episteme 12(3), pp. 363-384.

Tolhurst, W. E. (1998) "Seemings," American Philosophical Quarterly 35(3), pp. 293302.

Tucker, C. (2010) "Why Open-Minded People Should Endorse Dogmatism," Philosophical Perspectives 24(1): 529-545.

van Inwagen, P. (1997) "Materialism and the Psychological Continuity Account of Personal Identity," Philosophical Perspectives 11, pp. 305-319.

Walton, K. (1990) Mimesis as Make-Believe: On the Foundations of the Representational Arts, Cambridge, MA: Harvard University Press.

Weinberg, J. M., Nichols, S., and Stich, S. (2001) "Normativity and Epistemic Intuitions," Philosophical Topics 29(1-2): 429-460.

Williamson, T. (2005) "Armchair Philosophy, Metaphysical Modality and Counterfactual Thinking," Proceedings of the Aristotelian Society 105, pp. 123.

Williamson, T. (2007) The Philosophy of Philosophy, Malden, MA: Blackwell. 